\title{
Potential role for bone marrow-derived fibrocytes in the orbital fibroblast heterogeneity associated with thyroid-associated ophthalmopathy
}

\author{
T. J. Smith \\ Department of Ophthalmology and Visual \\ Sciences and Division of Metabolism and \\ Endocrine Diseases, and Department of Internal \\ Medicine, University of Michigan Medical School, \\ Ann Arbor, MI, USA
}

Accepted for publication 2 June 2010 Correspondence: T. J. Smith, Department of Ophthalmology and Visual Sciences, Kellogg Eye Center, 1000 Wall Street, Ann Arbor, MI 48105, USA.

E-mail: terrysmi@med.umich.edu

\begin{abstract}
Summary
Fibroblast heterogeneity has been recognized for decades, but the basis for multiple phenotypes among these cells has been investigated only recently. More than 15 years ago, Bucalla and his colleagues described for the first time a population of fibroblast-like cells among circulating mononuclear blood cells. Subsequently these mesenchymal cells, termed fibrocytes, have been characterized and found to participate in normal and pathological tissue remodelling. In this review, I have attempted to present the evidence generated thus far suggesting that fibrocytes are participants in autoimmune diseases where tissues are injured and undergo remodelling. Aspects of their phenotype suggest that they are well suited to help orchestrate immune responses through mononuclear cell recruitment and their ability to produce inflammatory mediators and extracellular matrix molecules. These attributes also raise the possibility that they might be useful targets against which therapeutic agents might be aimed.
\end{abstract}

Keywords: connective tissue, Graves' disease, inflammation, molecular biology, ophthalmopathy

\section{Introduction}

Fibroblast heterogeneity has been appreciated for several decades but its biological significance and the basis for cellular diversity remain uncertain. The question of why fibroblasts from distant anatomical regions should exhibit phenotypic divergence is unanswered. Moreover, a mechanism that might account for dissimilar fibroblasts inhabiting specific tissues has not been identified. Three connective tissue depots from which fibroblasts have been studied with considerable rigour include lung, joint and orbital connective tissue [1-4]. The origins and phenotypic characteristics of the fibroblasts found in these tissues have become increasingly important as investigation into the nature of organspecific autoimmune diseases proceeds. The concept that localization of systemic diseases could result, at least in part, from the peculiarities exhibited by fibroblasts in affected tissues continues to attract substantial discussion. However, significant advances have been made recently in our ability to distinguish between similarly appearing cells with 'fibroblast-like' morphologies. Despite these new insights, substantial imprecision persists in identifying the diverse biological roles of cells that resemble each other. At the heart of the problem lingers the absence of a single, specific marker that could distinguish fibroblasts from all other cells. Once characterized, such a protein would undoubtedly prove invaluable in elucidating more clearly the molecular mechanisms and cellular interactions that underlie normal and pathological tissue remodelling.

\section{The orbital fibroblast: an example of cellular diversity}

Orbital fibroblasts comprise a heterogeneous population of cells that can be separated into discrete subsets based on their display of surface markers [5]. The most frequently studied of these is Thy-1, which has been used by several investigators to discriminate between those fibroblasts that can differentiate into myofibroblasts $\left(\right.$ Thy- $\left.1^{+}\right)$and those capable of becoming adipocytes $\left(\right.$ Thy- $\left.1^{-}\right)[6,7]$. This assignment is also true for fibroblasts from lung $[8,9]$. When Thy- $1^{+}$fibroblasts are exposed to transforming growth factor (TGF)- $\beta$, they differentiate into myofibroblasts. In contrast, Thy-1 fibroblasts terminally differentiate into adipocytes when proliferator-activated receptor (PPAR) $\gamma$ is activated with prostaglandin $\mathrm{J}_{2}$ or thiazolidinediones such as rosiglitazone. Whether these distinctions hold true for cells in vivo is not yet known. The basis for the cellular diversity observed in these connective tissue depots has yet to be determined, but may ultimately explain the patterns of tissue 
remodelling observed in both anatomic regions. With regard to the orbit, the potential for Thy- $1^{-}$fibroblasts to differentiate into adipocytes might help to explain the apparent expansion of fat found in Graves' disease.

\section{Infiltration of fibrocytes into tissues might contribute to apparent fibroblast diversity}

Fibrocytes represent circulating bone-marrow derived monocyte lineage cells that present antigen efficiently to lymphocytes, prime naive $\mathrm{T}$ cells and can enter sites of tissue injury $[10,11]$. They are distinct from fibroblasts, $\mathrm{T}$ and $\mathrm{B}$ lymphocytes, monocytes, epithelial, endothelial and dendritic cells and can differentiate into mature fat cells, osteoblasts and myofibroblasts. Their ultimate fate depends, at least in part, upon the signals they receive from their microenvironment and which of the intracellular signalling pathways become activated [12]. In this regard, fibrocytes resemble fibroblasts. Fibrocytes were first described by Bucalla etal. in 1994 as possessing a $\mathrm{CD} 4^{+}$vimentin $^{+}$collagen ${ }^{+}$phenotype [10], They were found capable of circulating as members of a population of peripheral blood mononuclear cells and were shown to enter wound chambers implanted in subcutaneous tissue. They were identified in connective tissue scars. Once fibrocytes have infiltrated injured target tissues undergoing remodelling, they assume a fibroblast-like morphology. Moreover, they appear to lose their surface expression of CD34 as they develop into fibroblasts [13], suggesting that this protein behaves as a progenitor marker. Fibrocytes are believed to interact with other mononuclear cells that have also been recruited from the circulation. They can also cross-talk with residential fibroblasts. Currently it is uncertain exactly what roles fibrocytes play in tissue regeneration or how they might participate in the formation of fibrosis. Moreover, the mechanisms and signalling pathways through which they exchange molecular information with other cells are only partially identified. A major hurdle in characterizing fibrocytes and distinguishing them from fibroblasts continues to result from the absence of specific surface markers. Identification of fibrocytes as a distinct cell type has resulted from a rigorous set of characterization studies which should now allow greater precision in classifying their biological functions and attributing them to specific subpopulations of cells.

\section{Characterization of the fibrocyte phenotype}

Initial studies examining the phenotype of fibrocytes involved observations made following their initiation and propagation in cell culture. Subsequently, their activities have been described in vivo. Much of what we now know about their behaviour has been generated in animal models. In mice, fibrocytes appear to develop from $\mathrm{CD} 115^{+} \mathrm{CD} 11 \mathrm{~b}^{+} \mathrm{Gr} 1^{+}$monocytes. When mouse splenocytes were cultured for 14 days, Niedermeier et al. [14] found an outgrowth of spindle-shaped cells. When analysed by flow cytometry, they appear as collagen I-expressing cells which also display a $\mathrm{CD} 45^{+} \mathrm{CD} 11 \mathrm{~b}^{+} \mathrm{CD} 16 / 32^{+}$phenotype but lack CXCR4, CD34 or CD115 expression. When depleted of certain leucocyte subsets such as CD11b ${ }^{+}, \mathrm{CD} 115^{+}, \mathrm{CD} 16 / 32^{+}$ or $\mathrm{Grl}^{+}$, considerably fewer fibrocytes are generated. A number of factors extrinsic to fibrocytes have been implicated in their regulation. Of particular interest, the study by Niedermeier et al. demonstrated that $\mathrm{CD} 4^{+}$lymphocytes support fibrocyte differentiation [14]. The presence of nonactivated $\mathrm{CD} 4^{+}$cells substantially enhances fibrocyte in vitro. Conversely, the absence of these lymphocytes reduces differentiation, both in vitro and in vivo. When activated, $\mathrm{CD}^{+} \mathrm{T}$ cells release TNF- $\alpha$, interleukin (IL)-4, interferon (IFN)- $\gamma$, and IL-2. The fibrosis induced by unilateral ureteral obstruction can be reduced substantially by IL- 2 and TNF- $\alpha$, as can the appearance of fibrocytes. When $\mathrm{CD}^{+}$cells undergo activation in the presence of calcineurin inhibitors such as cyclosporin, they promote collagen deposition and enhance fibrocyte accumulation in this model. Why fibrocytes are induced to infiltrate kidneys following unilateral ureteral obstruction, but are relatively rare in renal tissues from similarly manipulated severe combined immunodeficiency (SCID) mice, might be attributable to the absence of lymphocytes in immunodeficient animals.

A recent study by Pilling et al. [15] has examined the markers that might be useful in distinguishing human fibrocytes from fibroblasts. In their remarkably detailed and exhaustive study, the authors found that among the cell types examined, only fibrocytes express the combination of CD45RO, 25F9 and S100A8/A9. They included in their study fibroblasts, macrophages and peripheral blood monocytes. Importantly, they concluded that CD34, CD68 and collagen fail to discriminate among these four cell types. Several cytokines, including IFN- $\gamma$, IL-4, IL-12, IL-13 and serum amyloid P, differentially affect the display of CD32, CD163, CD172a and CD206 in fibrocytes and macrophages [15]. Human fibrocytes express a diverse array of cytokines, including TNF- $\alpha$, IL-1 $\beta$, IL-10, monocyte chemoattractant protein (MCP), macrophage inflammatory protein (MIP)-1 $\alpha$, MIP-1 $\beta$, MIP-2, platelet-derived growth factor (PDGF)-A, TGF- $\beta 1$ and macrophage colony-stimulating factor (M-CSF). Moreover, treatment of fibrocytes with exogenous IL- $1 \beta$ induced IL-6, IL-8, IL-10, MCP-1, MIP- $1 \alpha$ and MIP-1 $\beta$. Thus the array of cytokines produced by fibrocytes, either under basal conditions or following activation by IL-1 $\beta$, appears to be very similar to that found in fibroblasts originating from a variety of tissues.

Regulation of fibrocyte trafficking to sites of injury and tissue repair apparently derives from a network of chemokines and chemoattractants. CXCR4 represents the principal chemokine receptor displayed on human fibrocytes. Its cognate ligand, CXCL12, is generated by several cell types. CXCL12 has been shown in several models to exert powerful 
chemotactic influence by fibrocytes and represents a major determinant for their infiltration of target tissues. In addition, CCR3, CCR5 and CCR7 are also expressed on the human fibrocyte surface $[16,17]$. A slightly different profile of receptors is found on animal fibrocytes. For instance, mouse fibrocytes display CXCR4, CCR2 and CCR7. PDGF, insulin-like growth factor (IGF) and epidermal growth factor (EGF) can induce CXCR4 mRNA [18]. Growth factor and hypoxia-driven CXCR4 display is mediated through the PI3 kinase/mTor pathway and can be inhibited by rapamycin, which substantially diminished the accumulation of fibrocytes in targeted tissues.

\section{Evidence for fibrocyte involvement in human diseases}

In the last few years, more attention has been focused upon the study of human fibrocytes and their potential abnormalities in disease. The research group led by Streiter has produced substantial evidence for fibrocytes playing an important role in lung fibrosis. In a series of reports, these investigators have demonstrated the remarkable plasticity with which fibrocytes can differentiate into either adipocytes or myofibroblasts, depending upon whether they are treated with an activator of PPAR $\gamma$ or TGF- $\beta[12,19]$. With regard to the former, troglitazone treatment resulted in the accumulation of lipid within the cytoplasm and the induction of the adipocyte-specific gene $a P 2$. In contrast, activation of $\mathrm{Smad} 2 / 3$ and stress-activated protein kinase/c-Jun $\mathrm{N}$-terminal kinase mitogen-activated protein kinase pathways results in the transition of fibrocytes to myofibroblasts and the induction of $\alpha$-smooth muscle actin. The potential for fibrocyte participation in autoimmune disease remains relatively unexplored. Bohle and co-workers [20] examined the pathogenic basis for chronic renal failure developing as a consequence of primary glomerulopathies. They reported that renal insufficiency can result from chronically inflamed renal cortical post-glomerular capillaries. Vessel narrowing can impair glomerular perfusion. The authors found evidence suggesting that material reabsorbed by tubules could then be presented as autoantigens to intraepithelial $\mathrm{T}$ cells, leading potentially to immune responses involving expanded numbers of fibroblasts and fibrocytes. In an attempt to determine the propensity of marmosets to autoimmune disease, Maile and Merker described the tissue architecture of the thyroid [21]. They found monocytes, macrophages, mast cells and fibrocytes and speculated that these cells participate in the frequent thyroid autoimmunity found in these animals. Using phospho-specific flow cytometry, Galligan et al. examined peripheral blood fibrocytes from patients with established rheumatoid arthritis of greater than 1 year duration [22]. They reported that both p44/42 extracellular regulated (Erk) and p38 arms of the mitogen-activated protein kinase (MAPK) pathway were activated in these fibrocytes, as were signal transducer and activator of tran- scription (STAT) 3 and STAT5. The levels of phosphorylation found in early versus established rheumatoid arthritis were similar, suggesting that the levels of signalling might prove invariant following disease initiation. In a mouse model of sclerosing cholangitis, designated $\mathrm{Abcb}^{-1-}$, Roderfeld and colleagues were able to demonstrate the involvement of both bone marrow-derived fibrocytes and hepatic stellate cells in biliary fibrogenesis [23].

Fibrocytes have been implicated in wound healing. This process is accelerated in mice deficient in leucocyte-specific protein 1 (LSP-1) [24], a molecule purported to represent a reliable fibrocyte marker. It was also suggested that LSP-1 display might help to discriminate fibrocytes from fibroblasts [25]. LSP-1 null mice were found to have increased levels of macrophages, neutrophils and fibrocytes in full-thickness skin wounds. These tissues were also found to have elevated levels of TGF- $\beta$ and vascular endothelial growth factor (VEGF) [24]. Similarly, bleomycin-induced fibrosis of the skin was enhanced in $L s p^{-/-}$mice [26]. Fibrocytes from patients with thermal burns and those from normal donors have substantially less capacity for collagen production than do dermal fibroblasts [27]. When conditioned medium from fibrocytes derived from burned individuals was incubated with dermal fibroblasts, they exhibited accelerated proliferation when compared to those incubated in medium from control fibrocytes. These effects could be blocked with TGF- $\beta$ neutralizing antibodies [27]. These same investigators have shown that IFN- $\alpha 2 \mathrm{~b}$ can reduce scar formation following thermal injury by attenuating fibrocyte activity and reducing their numbers [28].

With regard to the kidney, the participation of bone marrow-derived stem cells remains controversial [29]. Results generated in a number of models of renal injury suggest that these stem cells can localize to specific areas of the kidney and might facilitate tissue regeneration. Thus, their therapeutic potential in several forms of human kidney dysfunction is under evaluation. The outcome of such studies will probably influence the research being conducted in allied disease processes involving other organs and tissues.

\section{Graves' disease as a model of fibrocyte participation in human autoimmunity: basis for orbital fibroblast heterogeneity?}

Graves' disease represents an autoimmune process where the thyroid becomes enlarged and overactive [30]. The basis for the over-production of thyroid hormones and gland enlargement in this disease involves the production and activity of autoantibodies targeting the thyrotrophin (aka thyroidstimulating hormone) receptor (TSHR). In addition, the IGF-1 receptor (IGF-1R) is over-expressed by orbital fibroblasts [31], B [32] and T cells [33,34] in patients with the disease. IGF-1R represents a second potentially pathogenic autoantigen that may account for abnormal thyroid 
enlargement and underlie the trafficking of lymphocytes to affected tissues, including the pretibial skin and orbit. Pritchard et al. [31] have suggested that T cell trafficking to the orbit in Graves' disease might be mediated through fibroblast responses to IGF-1 and Graves' disease-immunoglobulin G (GD-IgG). When exposed to either agent, these fibroblasts express high levels of the T cell chemoattractants, IL-16 and regulated on activation normal $\mathrm{T}$ cell expressed and secreted (RANTES). The fibroblast response is mediated through IGF-1R activation and post-receptor signalling through the FRAP/mTor/Akt/p70 $0^{\text {s6k }}$ pathway. It is absent in fibroblasts derived from healthy donors [35]. In addition to the generation of chemoattractants, thyroid-associated ophthalmopathy (TAO) orbital fibroblasts synthesize high levels of hyaluronan, in response to either GD-IgGs or IGF-1. Hyaluronan is a non-sulphated glycosaminoglycan, the accumulation of which is thought to result in tissue oedema [36].

Orbital connective tissue derives in large part from neural ectoderm [37]. This tissue has a special propensity for inflammation. Approximately $30 \%$ of those individuals with Graves' disease also develop clinically important involvement of the orbit tissues surrounding the eye, a manifestation referred to as TAO. In this connective tissue component, the orbit becomes inflamed, and infiltrated with $\mathrm{T}$ and $\mathrm{B}$ lymphocytes and mast cells [38]. The cytokines and diseasemediating factors generated by these infiltrating cells are currently thought to activate resident fibroblasts which exhibit a unique phenotype. Orbital fibroblasts comprise a heterogeneous population of cells, especially those derived from patients with TAO [39]. The cellular attributes peculiar to orbital fibroblasts are thought to underlie the susceptibility of the orbit to the manifestations of Graves' disease. For instance, these fibroblasts exhibit particularly robust responses to proinflammatory cytokines such as the members of the IL- 1 family. When activated by IL- $1 \beta$, leucoregulin or CD154, orbital fibroblasts, especially those from patients with TAO, produce unusually high levels of hyaluronan [40]. This results from the induction of hyaluronan synthase (HAS) 1, 2 and 3 [41] and uridylyltransferase (UDP) glucose dehydrogenase [42]. The exaggerated induction of HAS isoforms could therefore account for the accumulation of hyaluronan in TAO. Activated orbital fibroblasts also express extremely high levels of IL-6, IL-8 and the prostaglandin endoperoxide $\mathrm{H}$ synthase-2, the inflammatory cyclooxygenase $[43,44]$. This latter induction, in turn, results in the production of extraordinarily high levels of prostaglandin $\mathrm{E}_{2}\left(\mathrm{PGE}_{2}\right)$ [45]. The prostanoid can exert an important bias on immune responses occurring in the orbit and favour T helper type 2 (Th2) predominance [46]. The magnitude of the induction of proinflammatory cytokines by orbital fibroblasts is remarkable but poorly understood. Cao and Smith reported the relatively low levels of secreted IL-1 receptor antagonist (IL-1RA) produced by these cells [47]. Low levels of IL-1RA generation achieved following exposure to IL-1 $\beta$ results in poorly opposed IL- $1 \alpha$ and IL-1 $\beta$ initiated signalling. Thus, the amplitude of cytokineprovoked downstream gene expression is substantially greater than that achieved in other fibroblast types.
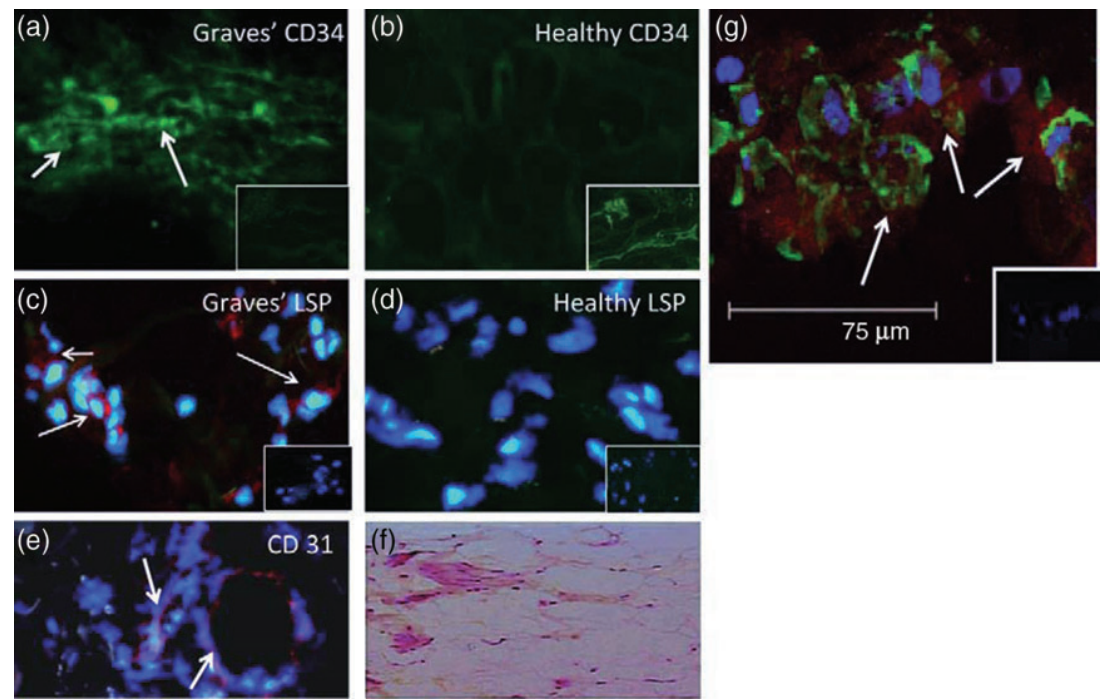

Fig. 1. CD $34^{+} \mathrm{LSP}_{-1}{ }^{+} \mathrm{TSHR}^{+}$fibrocytes can be identified in the orbital tissue of patients with TAO but are absent in tissues from healthy donors. (a) CD34 expression (arrows, green FITC) in TAO-derived tissue (inset, negative control staining). (b) Absent CD34 expression in healthy tissue (inset, positive staining control). (c) LSP-1 expression in TAO-derived tissue [red, arrows, nuclei counterstained with DAPI (blue)] (inset negative control). (d) Absence of LSP-1 expression in healthy tissue (inset negative control). (e) CD31 expression in disease-derived tissue is limited to vascular endothelium (red, arrows). (f) $\mathrm{H}$ and $\mathrm{E}$ stained consecutive thin-sections of the same orbital tissue (40×). (g) Fibrocytes present in orbital tissue from patients with TAO co-express CD34 and TSHR. Nuclei were counterstained with DAPI (blue). Thin sections were then subjected to confocal microscopy. Inset contains a negative staining control. (Reprinted with permission; Douglas, RS et al. Increased generation of fibrocytes in thyroid-associated ophthalmopathy, Copyright 2010, The Endocrine Society.) 
The basis for the heterogeneity displayed by orbital fibroblasts is yet to be understood [48]. When sorted on the basis of whether or not they display Thy-1 (CD90), orbital fibroblasts can be categorized broadly as those possessing the potential to become adipocytes (Thy- $1^{-}$) and those that can differentiate into myofibroblasts (Thy- $1^{+}$) subsets [6]. Fibroblasts destined to become fat cells can do so spontaneously in culture or more efficiently when treated with prostacyclin together with compounds that increase intracellular cyclic adenosine-5'-monophosphate (cAMP) levels or with molecules that bind and activate PPAR $\gamma[6,7]$. Conversely, Thy $-1^{+}$fibroblasts differentiate into myofibroblasts that express high levels of smooth muscle actin. This occurs following their exposure to TGF- $\beta$. Accompanying their transition to adipocytes, levels of TSHR are increased substantially [49], but what fibroblast subsets display TSHR specifically, and are these receptor molecules functional?

Douglas and colleagues [50] have reported very recently that the frequency of fibrocytes circulating in patients with Graves' disease is elevated above the levels found in healthy individuals. As others have reported previously, this study suggested that fibrocyte generation from cultured peripheral blood mononuclear cells (PBMCs) derived from donors without any known chronic diseases were vanishingly rare. In contrast, cultured PBMCs from many patients with Graves' disease, regardless of duration, thyroidal status or treatment received, generated numerous fibrocytes that exhibited the expected $\mathrm{CD} 34^{+} \mathrm{Col} 1^{+} \mathrm{CXCR} 4^{+}$phenotype. Interestingly, the elevated frequency of fibrocyte generation was not universal among patients with the disease. Many of these individuals, even those with recent onset and clinically severe disease, failed to generate fibrocytes at levels differing from those found in the control donors. The authors found relatively high levels of IGF-1R on fibrocytes, but the levels appear to be no different from those on fibrocytes donated by control subjects.

The report by Douglas et al. [50] began to characterize the phenotypic attributes of fibrocytes found in Graves' disease. Those studies aimed at identification of those cellular features that might underlie their participation in TAO. The authors found that $\mathrm{CD} 34^{+} \mathrm{Col} 1^{+} \mathrm{IGF}-1 \mathrm{R}^{+}$cells were relatively abundant in situ in orbital tissue from patients with TAO but were absent in those from healthy donors (Fig. 1). They were consistently $\mathrm{CD} 31^{-}$, indicating that the putative fibrocytes were unrelated to endothelial cells. Surprisingly, high levels of TSHR were detected on the circulating fibrocyte surface. The levels of this protein appear equivalent to those found on thyroid epithelial cells, where they mediate thyroid hormone production (Fig. 2). Even more surprising was their observation that the receptor is functional. When ligated with bovine thyroid-stimulating hormone (bTSH) or M22, an activating monoclonal antibody generated against TSHR, the production of inflammatory cytokines such as TNF- $\alpha$ and IL- 6 is up-regulated dramatically (Fig. 3) [50]. When orbital fibroblasts from patients with TAO were subjected to flow cyto-

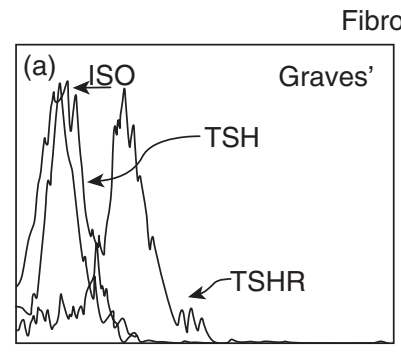

Fibrocytes
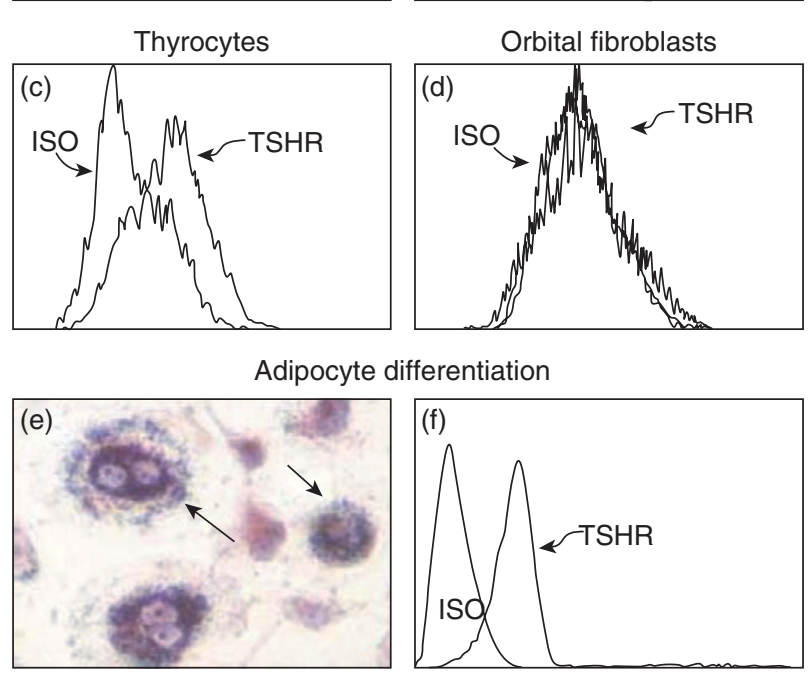

Fig. 2. Fibrocytes cultivated from peripheral blood mononuclear cells (PBMCs) express high levels of thyroid-stimulating hormone receptor (TSHR) regardless of whether they derive from (a) patients with Graves' disease or (b) healthy donors. (c) These levels are comparable to those found on primary human thyroid epithelial cells. (d) In contrast, undifferentiated orbital fibroblasts fail to express TSHR. (e) Fibrocytes differentiated into adipocytes accumulate intracellular lipid droplets staining with Oil Red O. (f) TSHR levels on fibrocytes remain elevated following differentiation. In (a), fibrocytes were preincubated with bovine thyroid-stimulating hormone (bTSH) $(5 \mathrm{mU} / \mathrm{ml})$ prior to staining with anti-TSHR antibodies. (Reprinted with permission; Douglas, RS et al. Increased generation of fibrocytes in thyroid-associated ophthalmopathy, Copyright 2010, The Endocrine Society.)

metric analysis, a subpopulation of cells was found to exhibit the $\mathrm{CD} 34^{+} \mathrm{Col}^{+}$phenotype. In contrast, $\mathrm{CD} 34^{+}$cells were uniformly absent among orbital fibroblasts from control donors. This phenotype was stable in culture over many serial passages. Moreover, it appears that the vast majority of CD $34^{+}$ orbital fibroblasts are also CD $90^{+}\left(\right.$Thy- $\left.1^{+}\right)$.

The finding that fibrocytes express high levels of TSHR and IGF-1R, coupled with their display of human leucocyte antigen D-related (HLA-DR), suggests that they might present autoantigens efficiently to $\mathrm{T}$ cells and in so doing could initiate antigen-specific immune responses. If this proves to be the case, the fibrocyte might represent an effective therapeutic target for early Graves' disease. As the phenotype of these cells becomes characterized more rigorously and the gene expression profile peculiar to fibrocytes 

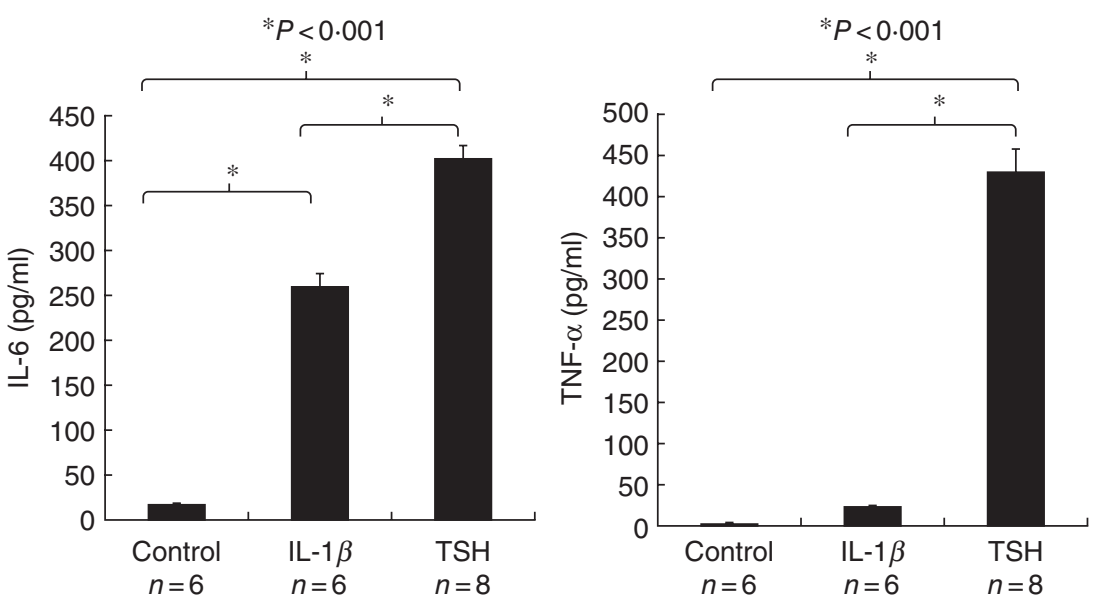

Fig. 3. Thyroid-stimulating hormone receptor (TSHR) displayed on fibrocytes generated from peripheral blood mononuclear cells (PBMCs) can function to initiate cytokine production. Cultured cells, in this case from a patient with Graves' disease, were treated with bovine thyroid-stimulating hormone (bTSH) $(5 \mathrm{mU} / \mathrm{ml})$ or interleukin (IL)-1 $\beta(10 \mathrm{ng} / \mathrm{ml})$ for $48 \mathrm{~h}$. The medium was subjected to enzyme-linked immunosorbent assays specific for (a) IL-6 or (b) tumour necrosis factor (TNF)- $\alpha$. Data are expressed as the mean \pm standard error of the mean of three replicate culture wells from a representative experiment $\left({ }^{*} P<0 \cdot 001\right)$. (Reprinted with permission; Douglas, RS et al. Increased generation of fibrocytes in thyroid-associated ophthalmopathy, Copyright 2010, The Endocrine Society.)

becomes identified, it may be possible to target them with specific molecular probes. This strategy could yield individualized therapies.

\section{Conclusions}

The involvement of the orbit in Graves' disease can serve as a potentially important model for fibrocyte behaviour in autoimmune diseases. Moreover, the cellular diversity found among fibroblasts inhabiting the human orbit might, at least in part, be reconciled by the recruitment of fibrocytes and their differentiation into cells exhibiting distinct phenotypes. A schematic of our theoretical model for TAO and the putative involvement of fibrocytes in that disease process are presented in Fig. 4. Orbital fibroblast diversity and their remarkable divergence from the phenotype more typically exhibited by fibroblasts from other tissues can, for the first time, be explained on the basis of their potential derivation from bone marrow-derived precursors. It is possible that this subset of fibroblasts is trafficked specifically to the orbit in TAO as a consequence of as-yet unidentified initiating processes. Once they have infiltrated the orbit, their potential
Fig. 4. Theoretical model of orbital fibroblast derivation and the molecular events occurring in thyroid-associated ophthalmopathy (TAO). HAS, hyaluronan synthase; TSHR, thyroid stimulating hormone receptor; IGF-1R, insulin-like growth factor-1 receptor; Col1, collagen 1 ; TNF- $\alpha$, tumour necrosis factor- $\alpha$.

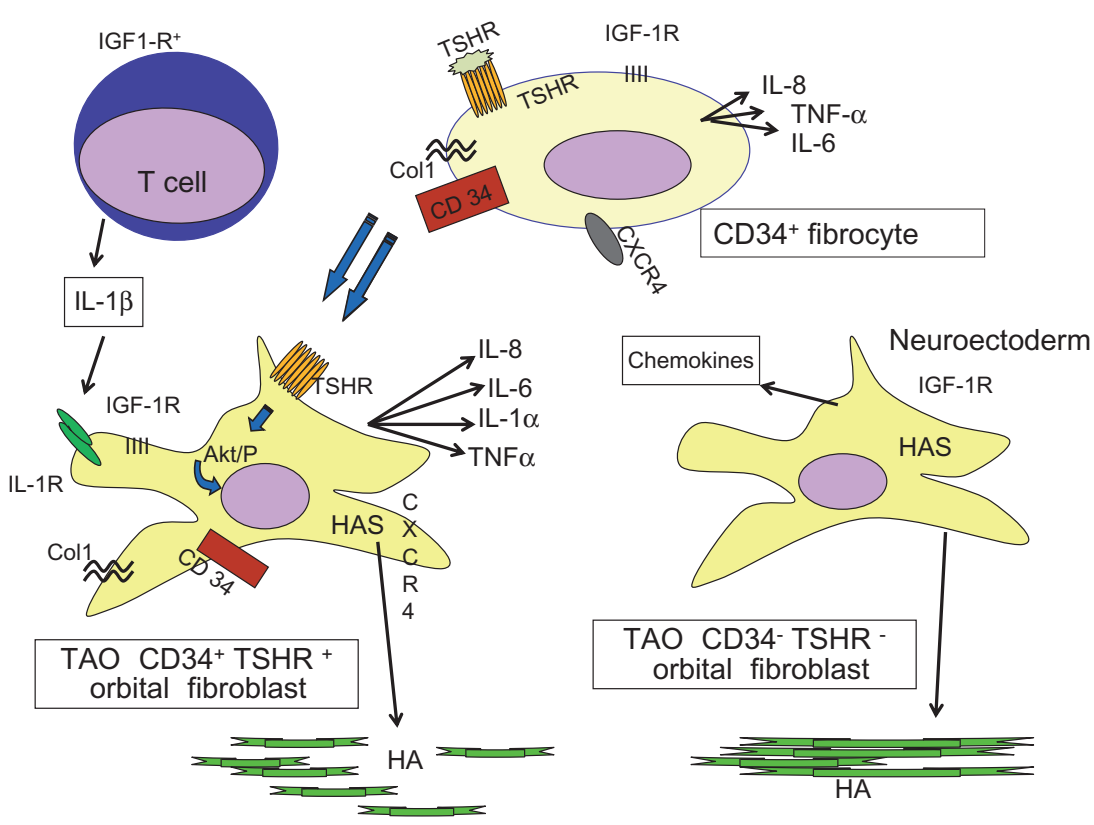


for differentiation into either adipocytes or myofibroblasts may underlie the characteristic tissue remodelling that occurs in the disease. The relative frequency of fibrocytes and the phenotypic peculiarities exhibited by them could potentially explain why expansion of orbital fat might dominate the pathology of some patients with TAO while others manifest muscle-predominant disease. Moreover, identifying fibrocytes as playing a pathogenic role in TAO might allow them to be targeted by therapeutic agents, a strategy which has been proposed previously for other diseases involving tissue remodelling and fibrosis [17]. Layered onto these characteristics is the recent finding that TSHR is expressed at relatively high levels by these cells. This disease-specific autoantigen is functional in fibrocytes and could mediate cytokine production as a consequence of the activating autoantibodies directed against TSHR that are also responsible for the overactive thyroid in Graves' disease. This brings to light another heretofore unanticipated potential role for fibrocytes. Could these cells participate in the breakdown of immune tolerance of TSHR? Alternatively, could display of this protein on the surface of fibrocytes function to enhance peripheral tolerance? The recent findings by Douglas and colleagues suggest a number of testable hypotheses and could ultimately provide the overarching framework for Graves' disease and potentially other forms of autoimmunity.

\section{Acknowledgements}

This work was supported in part by National Institutes of Health grants EY008976, EY11708 and DK63121 and by Research to Prevent Blindness.

\section{Disclosure}

The author has nothing to disclose.

\section{References}

1 Muller-Ladner U, Gay RE, Gay S. Structure and function of synoviocytes. In: Koopman WJ, ed. Arthritis and allied conditions: a textbook of rheumatology, 14th edn. Philadelphia: Lippincott, Williams \& Wilkins, 1997:243-54.

2 Tran CN, Thacker SG, Louie DM et al. Interactions of T cells with fibroblast-like synoviocytes: role of the B7 family costimulatory ligan B7-H3. J Immunol 2008; 180:2989-98.

3 Sempowski GD, Beckmann MP, Derdak S, Phipps RP. Subsets of murine lung fibroblasts express membrane-bound and soluble IL-4 receptors. Role of IL-4 in enhancing fibroblast proliferation and collagen synthesis. J Immunol 1994; 152:3606-14.

4 Smith TJ. Orbital fibroblasts exhibit a novel pattern of responses to proinflammatory cytokines: potential basis for the pathogenesis of thyroid-associated ophthalmopathy. Thyroid 2002; 12:197-203.

5 Smith TJ. Fibroblast biology in thyroid diseases. Curr Opin Endocrinol Diabetes 2002; 9:393-400.

6 Koumas L, Smith TJ, Phipps RP. Fibroblast subsets in the human orbit: Thy- $1^{+}$and Thy- $1^{-}$subpopulations exhibit distinct phenotypes. Eur J Immunol 2002; 32:477-85.

7 Smith TJ, Koumas L, Gagnon A et al. Orbital fibroblast heterogeneity may determine the clinical presentation of thyroid-associated ophthalmopathy. J Clin Endocrinol Metab 2002; 87:385-92.

8 Derdak S, Penney DP, Keng P, Felch ME, Brown D, Phipps RP. Differential collagen and fibronectin production by Thy $1^{+}$and Thy $1^{-}$lung fibroblast subpopulations. Am J Physiol 1992; 263:L283-90.

9 Fries KM, Blieden T, Looney RJ et al. Short analytical review evidence of fibroblast heterogeneity and the role of fibroblast subpopulations in fibrosis. Clin Immunol Immunopathol 1994; 72:283-92.

10 Bucala R, Spiegel LA, Chesney J, Hogan M, Cerami A. Circulating fibrocytes define a new leukocyte subpopulation that mediates tissue repair. Mol Med 1994; 1:71-81.

11 Bucala R. Circulating fibrocytes: cellular basis for NSF. J Am Coll Radiol 2008; 5:36-9.

12 Hong KM, Belperio JA, Keane MP, Burdick MD, Strieter RM. Differentiation of human circulating fibrocytes as mediated by transforming growth factor- $\beta$ and peroxisome proliferator-activated receptor $\gamma^{*}$. J Biol Chem 2007; 282:22910-20.

13 Schmidt M, Sun G, Stacey MA, Mori L, Mattoli S. Identification of circulating fibrocytes as precursors of bronchial myofibroblasts in asthma. J Immunol 2003; 171:380-9.

14 Niedermeier M, Reich B, Gomez MR et al. CD4 ${ }^{+} \mathrm{T}$ cells control the differentiation of $\mathrm{Grl}^{+}$monocytes into fibrocytes. Proc Natl Acad Sci USA 2009; 106:17892-7.

15 Pilling D, Fan T, Huang D, Kaul B, Gomer RH. Identification of markers that distinguish monocyte-derived fibrocytes from monocytes, macrophages, and fibroblasts. PLoS ONE 2009; 4:e7475.

16 Ishida Y, Kimura A, Kondo $\mathrm{T}$ et al. Essential roles of the CC chemokine ligand 3-CC chemokine receptor 5 axis in bleomycininduced pulmonary fibrosis through regulation of macrophage and fibrocyte infiltration. Am J Pathol 2007; 170:843-54.

17 Mehrad B, Burdick MD, Strieter RM. Fibrocyte CXCR4 regulation as a therapeutic target in pulmonary fibrosis. Int J Biochem Cell Biol 2009; 41:1708-18.

18 Phillips RJ, Mestas J, Gharaee-Kermani M et al. Epidermal growth factor and hypoxia-induced expression of CXC chemokine receptor 4 on non-small cell lung cancer cells is regulated by the phosphatidylinositol 3-kinase/PTEN/AKT/mammalian target of rapamycin signaling pathway and activation of hypoxia induced factor-1 $\alpha$. J Biol Chem 2005; 280:22473-81.

19 Crossno JT, Majka SM, Grazia T, Gill RG, Klemm DJ. Rosiglitazone promotes development of a novel adipocyte population from bone marrow-derived circulating progenitor cells. J Clin Invest 2006; 116:3220-8.

20 Bohle A, Wehrmann M, Mackensen-Haen S et al. Pathogenesis of chronic renal failure in primary glomerulopathies. Nephrol Dial Transplant 1994; 9:4-12.

21 Maile S, Merker HJ. The interstitial space of the thyroid gland of marmosets (Callithrix jacchus). Ann Anat 1995; 177:347-59.

22 Galligan CL, Siminovitch KA, Keystone EC, Bykerk V, Perez OD, Fish EN. Fibrocyte activation in rheumatoid arthritis. Rheumatology 2010; 49:640-51.

23 Roderfeld M, Rath T, Voswinckel R et al. Bone marrow transplantation demonstrates medullar origin of $\mathrm{CD} 34^{+}$fibrocytes and ameliorates hepatic fibrosis in $A b c b 4^{-1-}$ mice. Hepatology 2010; 51:267-76.

24 Wang J, Jiao H, Stewart TL et al. Accelerated wound healing in 
leukocyte-specific, protein 1-deficient mouse is associated with increased infiltration of leukocytes and fibrocytes. J Leukoc Biol 2007; 82:1554-63.

25 Yang L, Scott PG, Dodd B et al. Identification of fibrocytes in postburn hypertrophic scar. Wound Rep Reg 2005; 13:398-404.

26 Wang J, Jiao H, Stewart TL, Shankowsky HA, Scott PG, Tredget EE. Increased severity of bleomycin-induced skin fibrosis in mice with leukocyte-specific protein 1 deficiency. J Invest Dermatol 2008; 128:2767-76.

27 Wang JF, Jiao H, Stewart TL, Shankowsky HA, Scott PG, Tredget EE. Fibrocytes from burn patients regulate the activities of fibroblasts. Wound Rep Reg 2007; 15:113-21.

28 Wang J, Jiao H, Stewart TL, Shankowsky HA, Scott PG, Tredget EE. Improvement in postburn hypertrophic scar after treatment with IFN-alpha2b is associated with decreased fibrocytes. J Interferon Cytokine Res 2007; 27:921-30.

29 Bussolati B, Hauser PV, Carvalhosa R, Camussi G. Contribution of stem cells to kidney repair. Curr Stem Cell Res Ther 2009; 4:2-8.

30 Davies TF. Graves' disease. In: Braverman LE, Utiger RD, eds. Werner and Ingbar's The thyroid: a fundamental and clinical text, 7th edn. Philadelphia: Lippincott-Raven, 1996:525-58.

31 Pritchard J, Han R, Horst N, Cruikshank WW, Smith TJ. Immunoglobulin activation of $\mathrm{T}$ cell chemoattractant expression in fibroblasts from patients with Graves' disease is mediated through IGF-1 receptor pathway. J Immunol 2003; 170:6348-54.

32 Douglas RS, Naik V, Hwang CJ et al. B cells from patients with Graves' disease aberrantly express the IGF-1 receptor: implications for disease pathogenesis. J Immunol 2008; 181:5768-74.

33 Douglas RS, Gianoukakis AG, Kamat S, Smith TJ. Aberrant expression of the IGF-1 receptor by $\mathrm{T}$ cells from patients with Graves' disease may carry functional consequences for disease pathogenesis. J Immunol 2007; 178:3281-7.

34 Douglas RS, Gianoukakis AG, Goldberg RA, Kamat S, Smith TJ. Circulating mononuclear cells from euthyroid patients with thyroid-associated ophthalmopathy exhibit characteristic phenotypes. Clin Exp Immunol 2007; 148:64-71.

35 Pritchard J, Horst N, Cruikshank W, Smith TJ. Igs from patients with Graves' disease induce the expression of T cell chemoattractants in their fibroblasts. J Immunol 2002; 168:942-50.

36 Smith TJ, Hoa N. Immunoglobulins from patients with Graves' disease induce hyaluronan synthesis in their orbital fibroblasts through the self-antigen, IGF-1 receptor. J Clin Endocrinol Metab 2004; 89:5076-80.

37 Noden DM. The role of the neural crest in patterning of avian cranial skeletal, connective and muscle tissues. Dev Biol 1983; 96:144-65.
38 Prabhakar BS, Bahn RS, Smith TJ. Current perspective on the pathogenesis of Graves' disease and ophthalmology. Endocr Rev 2003; 24:802-35.

39 Smith TJ. Unique properties of orbital connective tissue underlie its involvement in Graves' disease. Minerva Endocrinol 2003; 28:110.

40 Smith TJ, Wang HS, Evans CH. Leukoregulin is a potent inducer of hyaluronan synthesis in cultured human orbital fibroblasts. Am J Physiol 1995; 268:C382-8.

41 Kaback LA, Smith TJ. Expression of hyaluronan synthase messenger ribonucleic acids and their induction by interleukin- $1 \beta$ in human orbital fibroblasts: potential insight into the molecular pathogenesis of thyroid-associated ophthalmopathy. J Clin Endocrinol Metab 1999; 84:4079-84.

42 Spicer AP, Kaback LA, Smith TJ, Seldin MF. Molecular cloning and characterization of the human and mouse UDP-glucose dehydrogenase genes. J Biol Chem 1998; 273:25117-24.

43 Sempowski GE, Rozenblit J, Smith TJ, Phipps RP. Human orbital fibroblasts are activated through CD40 to induce proinflammatory cytokine production. Am J Physiol 1998; 274:C707-14.

44 Wang HS, Cao HJ, Winn VD et al. Leukoregulin induction of prostaglandin-endoperoxide $\mathrm{H}$ synthase-2 in human orbital fibroblasts. J Biol Chem 1996; 271:22718-28.

45 Han R, Tsui S, Smith TJ. Up-regulation of prostaglandin $E_{2}$ synthesis by interleukin- $1 \beta$ in human orbital fibroblasts involves coordinate induction of prostaglandin-endoperoxide $\mathrm{H}$ synthase- 2 and glutathione-dependent prostaglandin $\mathrm{E}_{2}$ synthase expression. J Biol Chem 2002; 277:16355-64.

46 Betz M, Fox BS. Prostaglandin $E_{2}$ inhibits production of Th1 lymphokines but not of Th2 lymphokines. J Immunol 1992; 146:10813.

47 Cao HJ, Han R, Smith TJ. Robust induction of PGHS-2 by IL-1 in orbital fibroblasts results from low levels of IL-1 receptor antagonist expression. Am J Physiol Cell Physiol 2002; 284:C142937.

48 Smith TJ, Sempowski GD, Wang H-S, Del Vecchio PJ, Lippe SD, Phipps RP. Evidence for cellular heterogeneity in primary cultures of human orbital fibroblasts. J Clin Endocrinol Metab 1995; 80:2620-5.

49 Tsui S, Naik V, Hoa N et al. Evidence for an association between thyroid-stimulating hormone and insulin-like growth factor 1 receptors: a tale of two antigens implicated in Graves' disease. J Immunol 2008; 181:4397-405.

50 Douglas RS, Afifiyan NF, Hwang CJ et al. Increased generation of fibrocytes in thyroid-associated ophthalmopathy. J Clin Endocrinol Metab 2010; 95:430-8. 